\title{
Papers
}

\section{Assessment of neurocognitive impairment after off-pump and on-pump techniques for coronary artery bypass graft surgery: prospective randomised controlled trial}

Vipin Zamvar, David Williams, Judith Hall, Nicola Payne, Clare Cann, Karen Young, S Karthikeyan, John Dunne

\begin{abstract}
Objective To assess neurocognitive impairment after the off-pump and on-pump techniques for coronary artery bypass graft surgery in patients with triple vessel disease.

Design Randomised controlled trial.

Setting University Hospital of Wales, Cardiff.

Participants 60 patients undergoing coronary artery

bypass graft surgery for triple vessel disease

prospectively randomised to the off-pump or on-pump technique.

Main outcome measures Change in scores in nine standard neuropsychometric tests administered preoperatively and at 1 and 10 weeks postoperatively. Results The on-pump group showed a significantly greater deterioration in scores for two and three tests at 1 week and 10 weeks postoperatively, respectively, than the off-pump group. The on-pump group also showed a significantly higher incidence of major deterioration in one of the tests both 1 week and 10 weeks postoperatively. The incidence of neurocognitive impairment at 1 week postoperatively was $27 \%$ (8 out of 30 ) in the off-pump group and $63 \%$ (19 out of 30$)$ in the on-pump group $(\mathrm{P}=0.004)$; and at 10 weeks postoperatively was $10 \%$ (3 out of 30 ) in the off-pump group and $40 \%$ (12 out of 30 ) in the on-pump group $(\mathrm{P}=0.017)$.

Conclusion Off-pump coronary artery bypass graft surgery results in less neurocognitive impairment than the on-pump technique.
\end{abstract}

\section{Introduction}

Coronary artery bypass graft surgery is one of the most commonly performed procedures. Advances in surgical techniques, anaesthetic management, and postoperative care resulted in a steady decline in mortality from the procedure during the 1980s and '90s, despite a gradual increase in the risk profile of patients. Neurological injury is an important complication after coronary artery bypass graft surgery. It comprises two types. $^{2}$ Type 1 injury includes stroke, transient ischaemic attack, and coma (incidence 3 to 6\%). Type 2 injury is more subtle and includes impairment of cognitive function. These are defects associated with atten- tion, concentration, short term memory, fine motor function, and speed of mental and motor responses. The incidence of neurocognitive impairment after cardiac surgery varies from $20 \%$ to $80 \% 0^{3-6}$ These defects are not always transient, and longitudinal assessment studies have shown a major impairment at 5 years $^{78}$; impairment immediately after surgery has been shown to correlate with long term impairment. ${ }^{8}$ Recent work has focused on the role of cardiopulmonary bypass in neurocognitive impairment, but the literature is inconclusive. $^{6-11}$ In recent years coronary artery bypass graft surgery without using cardiopulmonary bypass (off-pump technique) has been shown to be a reliable and reproducible technique, and both short and medium term results have been favourable. ${ }^{12} 13$

Patients with single and double vessel disease are increasingly being managed by percutaneous coronary interventions. Most patients undergoing coronary artery bypass graft surgery have triple vessel disease. We aimed to assess the impact of the on-pump and off-pump techniques on neurocognitive impairment in patients undergoing coronary artery bypass graft surgery for triple vessel disease.

\section{Methods}

Patient selection

We enrolled 60 patients undergoing urgent or elective coronary artery bypass graft surgery for triple vessel disease between May and October 2001. All patients gave written informed consent. We excluded patients with a greater than $50 \%$ carotid artery stenosis, recent myocardial infarction (within one month), previous transient ischaemic attack or cerebrovascular attack, previous psychiatric illness, renal failure, or those who needed emergency operation, reoperation, or combined valvular surgery. We screened 76 patients; 10 had one or more of the exclusion criteria leaving 66 eligible for randomisation (figure). Two patients refused to take part and four were not invited because they were last minute additions to the operating list and therefore precluded performance of the neuropsychometric tests. We randomised the patients into two groups using sequentially numbered, sealed, opaque envelopes containing computer generated random allocations. We randomised 30 patients to receive conven-

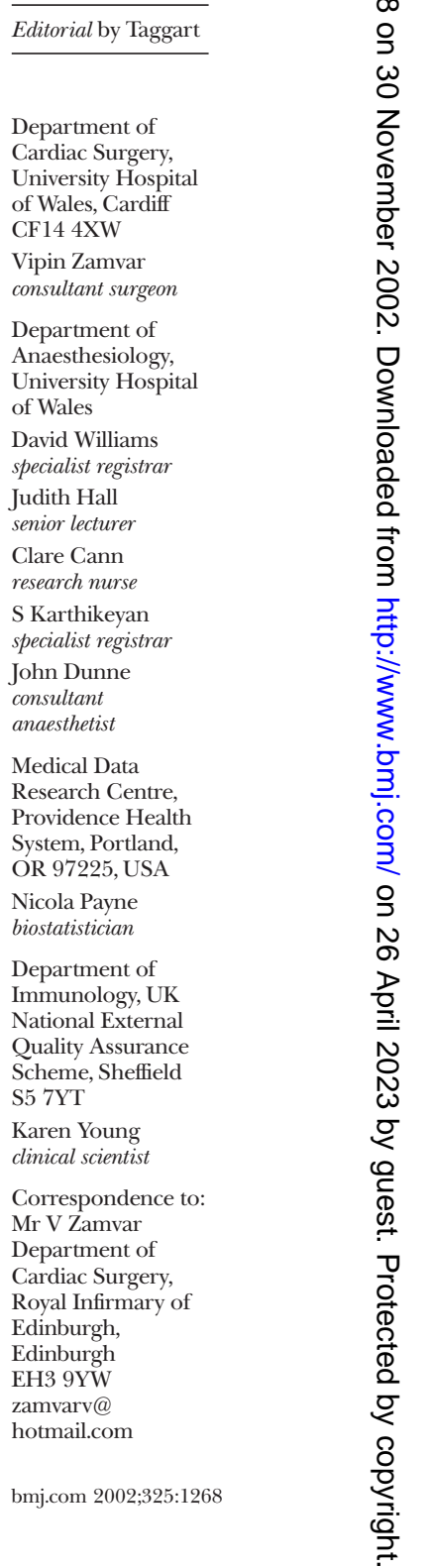


Table 1 Preoperative clinical data. Values are numbers of patients unless stated otherwise

\begin{tabular}{lcc} 
Variable & On-pump ( $\mathbf{n}=\mathbf{3 0})$ & Off-pump $(\mathbf{n}=\mathbf{3 0})$ \\
\hline Mean (SD) age (years) & $61.6(10)$ & $63.5(9.1)$ \\
\hline Male & 27 & 25 \\
\hline Angina class: & 0 & 0 \\
\hline Grade 1 & 8 & 5 \\
\hline Grade 2 & 19 & 22 \\
\hline Grade 3 & 3 & 3 \\
\hline Grade 4 & 30 & 30 \\
\hline Three vessel disease & 2 & 4 \\
\hline Left main stem lesion $(>50 \%)$ & 23 & 23 \\
\hline Left ventricular function (ejection fraction): & 6 \\
\hline Good $(>50 \%)$ & 5 & 1 \\
\hline Fair $(30-50 \%)$ & 2 & \\
\hline Poor $(<30 \%)$ & 23
\end{tabular}

tional on-pump coronary artery bypass graft surgery (group A) and 30 to receive the off-pump technique (group B). The operations were performed by one surgeon (VZ) at the University Hospital of Wales, Cardiff. We obtained ethical approval for our study from the Bro Taf local research ethics committee.

The anaesthetic technique was standardised and all patients received the same medication. The surgical technique was standardised, the left internal mammary artery being attached to the left anterior descending artery, and vein grafts to the other coronary arteries as appropriate in all patients. In both groups the top end anastomoses were constructed with the help of a side biting clamp. The only difference between the two groups was the use of cardiopulmonary bypass. Cardiotomy suction was not used in the on-pump group. In both groups the cell saver was used.

\section{Neuropsychometric assessment}

We carried out nine neuropsychometric tests to assess the patients both preoperatively and at 1 week and 10 weeks postoperatively. A qualified examiner (CC), blinded to treatment allocation, carried out the tests in a standardised fashion, in the same order. The battery of tests included the core tests according to the recommendations of the statement of consensus on assessment of neurobehavioural outcomes after cardiac surgery. ${ }^{14}$ The tests comprised the Rey auditory verbal learning test, part $\mathrm{A}$ and part $\mathrm{B}$ of the trail making test, the digit symbol substitution test, the digit

Table 2 Operative details and postoperative details. Values are numbers of patients unless stated otherwise

\begin{tabular}{lccc} 
Variable & On-pump (n=30) & Off-pump (n=30) & P value \\
\hline Mean (SD) No of grafts; range & $2.93(0.45) ; 2-4$ & $2.93(0.37) ; 2-4$ & 1 \\
\hline No of grafts: & 4 & & \\
\hline 2 grafts & 24 & 26 & \\
\hline 3 grafts & 2 & & \\
\hline 4 grafts & $29.9(8.9) ; 20-62$ & & \\
\hline Mean (SD) cross clamp time (min); range & $54.7(14.8) ; 36-104$ & & \\
\hline Mean (SD) cardiopulmonary bypass time & & & \\
(min); range & 7 & 0.34 \\
\hline Low cardiac output: & 0 & 10 & 0.18 \\
\hline Ionotropes & 10 & $7.9(9.4)$ & 0.23 \\
\hline Intra-aortic balloon pump & 23 & $7.6(2.7)$ & 0.23 \\
\hline Postoperative atrial fibrillation & $10.7(7.8)$ & & \\
\hline Transfused patients & $9(5.5)$ & & \\
\hline Mean (SD) ventilation (h) & & & \\
\hline Mean (SD) discharge (days) & & & \\
\hline
\end{tabular}

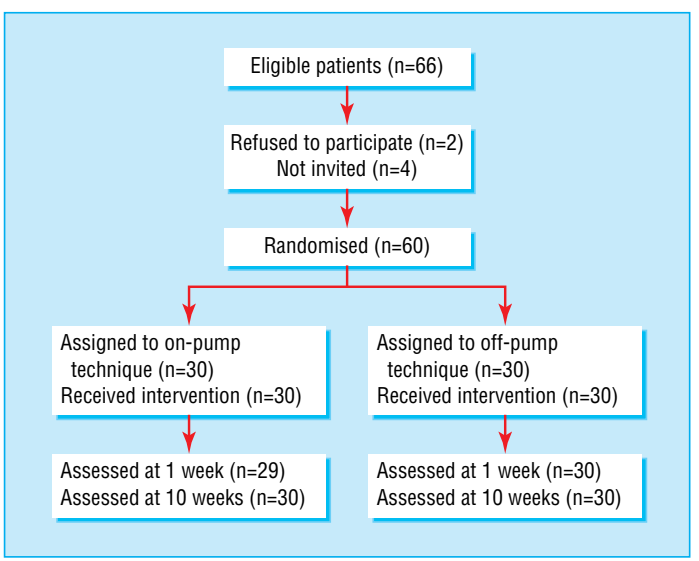

Flow of participants through trial

span forward and the digit span backward test, the grooved pegboard test using the dominant hand and the non-dominant hand, and the controlled oral word association test. We estimated the premorbid full scale IQ by using the national adult reading test. ${ }^{15}$

\section{Statistical analysis}

We expressed continuous data as means (standard deviations) and compared them by using the independent sample $t$ test or Mann-Whitney $\mathbf{U}$ test as appropriate. We compared proportions with $\chi^{2}$ tests with continuity correction or Fisher's exact test as appropriate.

The primary outcome variable was the change in scores at 10 weeks from preoperative levels, assessed by repeated measures analysis of variance with post hoc comparison and Bonferroni correction. We considered a patient to have major deterioration in a particular test if the score deteriorated by $1 \mathrm{SD}$ of the baseline score of all patients. ${ }^{16}$ We considered a patient to have neurocognitive impairment if there was a major deterioration in two or more tests. ${ }^{16}$ We used the $\chi^{2}$ test to compare the proportion of patients with neurocognitive deterioration in the two groups.

Our sample size was based on data obtained from a previous non-randomised study performed in our department (unpublished data). The standardised difference was 1 . To achieve a power of $87 \%$ we needed 40 patients (20 per group), with an $\alpha$ error set at 0.05 (two sided). Overall, we recruited 60 patients (30 in each group) to allow for loss to follow up and conversions to the other technique during surgery.

We performed all analyses with the SPSS10 software package. We present $95 \%$ confidence intervals for the main results. We considered a $\mathrm{P}$ value of $<0.05$ as significant.

\section{Results}

Table 1 shows the patient characteristics in both groups. Both groups were similar for age, sex, angina class, left ventricle function, and extent of coronary artery disease, and they had a similar number of grafts (table 2). Neither group had any deaths, major neurological complications, or perioperative myocardial infarctions (based on electrocardiographic evidence only). Intubation time and length of hospital stay were shorter in the off-pump group than in the 
Table 3 Mean (SD) preoperative scores for all tests, and full scale IQ and mean differences for all tests*

\begin{tabular}{|c|c|c|c|c|c|c|c|c|}
\hline \multirow[b]{2}{*}{ Test } & \multicolumn{2}{|c|}{ Mean (SD) preoperative scores } & \multicolumn{3}{|c|}{ Mean difference 7 days postoperatively } & \multicolumn{3}{|c|}{ Mean difference 10 weeks postoperatively } \\
\hline & Off-pump ( $n=30)$ & On-pump (n=30) & Off-pump ( $n=30)$ & On-pump (n=29) & $P$ value & Off-pump (n=30) & On-pump ( $n=30)$ & $P$ value \\
\hline Rey auditory verbal learning test & $36(8.83)$ & $35.2(8.99)$ & $-1.20(4.1)$ & $-2.58(10.0)$ & 0.98 & $2.60(9.2)$ & $1.33(8.0)$ & 0.99 \\
\hline Part $A$ of trail making test & $43.57(15.41)$ & $40.37(14.22)$ & $-6.20(17.8)$ & $-13.55(15.5)$ & 0.20 & $3.00(8.6)$ & $1.63(13.0)$ & 0.99 \\
\hline $\begin{array}{l}\text { Grooved pegboard test using } \\
\text { dominant hand }\end{array}$ & $99.93(48.52)$ & $91.20(38.05)$ & $-5.33(32.5)$ & $-13.44(37.2)$ & 0.76 & $4.20(14.1)$ & $-20.70(22.9)$ & $<0.002$ \\
\hline $\begin{array}{l}\text { Grooved pegboard test using } \\
\text { non-dominant hand }\end{array}$ & $109.37(37.99)$ & $106.57(42.45)$ & $-4.53(26.0)$ & $-32.27(35.2)$ & 0.002 & $3.63(15.2)$ & $0.80(36.2)$ & 0.99 \\
\hline Digit symbol substitution test & $42.47(10.23)$ & $42.80(18.19)$ & $-1.50(8.1)$ & $-7.34(9.6)$ & 0.028 & $2.83(6.7)$ & $-4.06(8.1)$ & 0.002 \\
\hline Digit span forward test & $9.00(2.48)$ & $8.97(2.37)$ & $-0.26(1.9)$ & $-0.75(2.5)$ & 0.78 & $0.36(1.4)$ & $-0.16(2.0)$ & 0.54 \\
\hline Digit span backward test & $6.43(2.27)$ & $6.57(2.47)$ & $-0.02(1.8)$ & $-1.14(2.9)$ & 0.14 & $0.67(1.3)$ & $0.97(0.9)$ & 0.84 \\
\hline Controlled oral word association test & $40.97(10.49)$ & $40.93(16.01)$ & $0.23(7.8)$ & $-0.79(16.8)$ & 0.99 & $2.23(7.9)$ & $1.66(10.4)$ & 0.99 \\
\hline Full scale IQ & $114.9(8.81)$ & $114.16(8.24)$ & & & & & & \\
\hline
\end{tabular}

$P$ values adjusted for multiple comparisons.

*Positive difference is improvement and negative difference is deterioration.

on-pump group but did not reach significance. Significantly fewer patients in the off-pump group required blood transfusion. Both groups had similar baseline scores for the neuropsychometric tests and full scale IQ (table 3).

\section{Change in scores}

One patient in the on-pump group was not tested 1 week postoperatively because of tiredness and loss of motivation. All patients were tested 10 weeks postoperatively. At 1 week postoperatively the on-pump group showed a significantly greater deterioration in scores in the grooved pegboard test using the non-dominant hand and the digit symbol substitution test than the off-pump group. At 10 weeks postoperatively the on-pump group showed a significantly greater deterioration in part $\mathrm{B}$ of the trail making test, the grooved pegboard test using the dominant hand, and the digit symbol substitution test (table 3).

\section{Patients with 1 SD or more deterioration in} individual tests

One week postoperatively two patients $(7 \%)$ in the offpump group and 14 patients (48\%) in the on-pump group showed a deterioration of $1 \mathrm{SD}$ or more in the grooved pegboard test using the non-dominant hand $(\mathrm{P}=0.001$; table 4$)$. Ten weeks postoperatively no patient in the off-pump group and six patients $(20 \%)$ in the on-pump group showed a deterioration of $1 \mathrm{SD}$ or more in the grooved pegboard test using the dominant hand $(\mathrm{P}=0.03)$. In the other tests the difference in the proportion of patients in each group did not reach significance.
Patients with neurocognitive impairment

Patients were considered to have neurocognitive impairment if they showed a deterioration of $1 \mathrm{SD}$ or more in two or more tests. One week postoperatively eight patients $(27 \%)$ in the off-pump group and 19 $(66 \%)$ in the on-pump group $(\mathrm{P}=0.004)$ had neurocognitive impairment. Ten weeks postoperatively three patients $(10 \%)$ in the off-pump group and $12(40 \%)$ in the on-pump group $(\mathrm{P}=0.017)$ had neurocognitive impairment.

\section{Discussion}

The incidence of neurocognitive impairment after coronary artery bypass graft surgery varies noticeably between studies. ${ }^{3-5} 16$ This is because of variations in the tests used, the time points of assessment, the definition of impairment, and the statistical methods used for comparing groups. ${ }^{16}$

We found significantly less neurocognitive impairment 1 week and 10 weeks after off-pump coronary artery bypass graft surgery for patients with triple vessel disease. Previous studies have shown equivocal results. One prospective randomised study found increased concentrations of $\mathrm{S} 100$ protein, a marker of neurological injury, in the on-pump group, but no difference in neurocognitive impairment. ${ }^{11}$ The definition of neurocognitive impairment was, however, unclear. More than $60 \%$ of patients recruited in that study had single or double vessel disease. Another study found a higher concentration of serum S100 protein, a higher number of high intensive transient signals picked up

Table 4 Percentage of patients in each group who had deterioration $\geqslant 1$ standard deviation in individual tests at 1 week and 10 weeks postoperatively

\begin{tabular}{|c|c|c|c|c|c|c|c|c|}
\hline \multirow[b]{3}{*}{ Test } & \multicolumn{4}{|c|}{1 week postoperatively } & \multicolumn{4}{|c|}{10 weeks postoperatively } \\
\hline & \multirow{2}{*}{$\begin{array}{c}\text { Off-pump } \\
(\mathrm{n}=30)\end{array}$} & \multirow{2}{*}{$\begin{array}{c}\text { On-pump } \\
(\mathrm{n}=29)\end{array}$} & \multicolumn{2}{|c|}{ Difference } & \multirow{2}{*}{$\begin{array}{c}\text { Off-pump } \\
(\mathrm{n}=30)\end{array}$} & \multirow{2}{*}{$\begin{array}{c}\text { On-pump } \\
(n=30)\end{array}$} & \multicolumn{2}{|c|}{ Difference } \\
\hline & & & $\%$ & $95 \% \mathrm{Cl}$ & & & $\%$ & $95 \% \mathrm{Cl}$ \\
\hline Rey auditory verbal learning test & 13.3 & 34.5 & 21.2 & $(-0.7$ to 41.0$)$ & 10.0 & 23.3 & 13.3 & $(-6.1$ to 32.1$)$ \\
\hline Part B of trail making test & 23.3 & 44.8 & 21.5 & $(-2.6$ to 42.6$)$ & 10.0 & 30.0 & 20.0 & $(-0.5$ to 39.0$)$ \\
\hline Grooved pegboard test using dominant hand & 13.3 & 31.0 & 17.7 & $(-3.7$ to 37.6$)$ & 0 & 20.0 & 20.0 & $(4.5 \text { to } 37.3)^{*}$ \\
\hline Grooved pegboard test using non-dominant hand & 6.7 & 48.3 & 41.6 & $(19.3 \text { to } 59.6)^{*}$ & 3.3 & 16.7 & 13.3 & $(-2.9$ to 30.5$)$ \\
\hline Digit span forward test & 10.0 & 27.6 & 17.6 & $(-2.7$ to 36.9$)$ & 0 & 10.0 & 10.0 & $(-3.1$ to 25.6$)$ \\
\hline Digit span backward test & 6.7 & 20.7 & 14.0 & $(-4.2$ to 32.4$)$ & 0 & 0 & 0 & $(-11.4$ to 11.4$)$ \\
\hline Controlled oral word association test & 6.7 & 27.6 & 20.9 & $(1.4 \text { to } 39.7)^{\star}$ & 3.3 & 10.0 & 6.7 & $(-8.2$ to 22.5$)$ \\
\hline
\end{tabular}

*Excludes 0. 
by transcranial Doppler, and an increased incidence of neurocognitive impairment in the on-pump than off-pump group. ${ }^{9}$ This was a randomised study including 40 patients. The neuropsychological assessment was limited to the preoperative period and 1 week postoperatively, and the tests used did not conform to the consensus statement. ${ }^{14}$ In one randomised controlled trial, neurocognitive outcome was assessed in 281 patients, using 10 neuropsychometric tests. ${ }^{6}$ Improved cognitive outcomes were found in the off-pump group at 3 months, but the effects were limited and became negligible at 12 months. A significant proportion of the patients in this study had single and double vessel disease $(76 \%)$; only $24 \%$ had triple vessel disease. Anaesthetic management differed between the groups: $99 \%$ of patients in the on-pump group received total intravenous anaesthesia including high dose opioids, and $54 \%$ of patients in the off-pump group received thoracic epidural anaesthesia.

\section{Strengths of study}

Overall, we included $91 \%$ of eligible patients in our trial. The operations were performed by a single surgeon (VZ). We standardised anaesthetic and surgical factors that might lead to cerebral injury. Both groups underwent the same surgical procedure, including the use of the same conduits and the same technique for proximal grafting. We included only patients with triple vessel disease. Previous studies have included a significant proportion of patients with single or double vessel disease. ${ }^{6-11}$ No cross over occurred. None of the patients in the off-pump group required conversion to on-pump surgery. Follow up was $100 \%$ at 10 weeks. Our prospective randomised trial produced two similar groups (table 1). We are thus confident that cardiopulmonary bypass was the only major difference between our study groups.

\section{Limitations of study}

One limitation of our study is that a single surgeon operating in a single hospital, with standardisation of the anaesthetic and surgical techniques allows reproducibility of findings, but generalisability is affected. Our findings need to be tested in a multicentric study with different surgeons and hospitals. Aortic atherosclerosis is an important factor in neurological and neurocognitive outcomes. We did not use epiaortic scanning or transoesophageal echocardiography to detect aortic atherosclerosis. Our patients were assessed only at 1 week and 10 weeks postoperatively. Although outcomes at 10 weeks may reflect more important longer term outcomes, they may not necessarily reflect any permanent sequelae. The incidence of neurocognitive outcome decreased from 1 to 10 weeks; future studies need to incorporate longer term follow up.

Cardiopulmonary bypass has been implicated in the pathogenesis of neurocognitive impairment. Various mechanisms are responsible, including hypoperfusion during cardiopulmonary bypass, venous hypertension due to manipulation of the heart during surgery, emboli originating from the cardiopulmonary bypass circuit and the ascending aorta, and systemic inflammatory response syndrome leading to cerebral swelling and an increase in the permeability of the blood-brain barrier. ${ }^{17-22}$
What is already known on this topic

Neurocognitive impairment after coronary artery bypass graft surgery occurs in a major proportion of patients

Cardiopulmonary bypass has been implicated, but the evidence is inconclusive

\section{What this study adds}

Off-pump coronary artery bypass graft surgery results in less neurocognitive impairment than the on-pump technique

Neuropsychometric testing and the measurement of serum levels of biochemical markers (S100 $\beta$ and neurone specific enolase) are two ways of measuring neurological injury. Neuropsychometric tests assess specific domains of the brain, whereas the serum markers assess global injury. Two studies showed an association between neurocognitive impairment and S100 $\beta$ and neurone specific enolase levels. ${ }^{14}{ }^{15}$ Others have found no such association. ${ }^{11}{ }^{23}$ Administering a comprehensive battery of neuropsychometric tests is time consuming. Development of a serum marker or a computerised objective test that could be administered in less time and that correlated well with the severity of neuropsychometric impairment would improve the work of future researchers. At present, comprehensive neuropsychometric tests need to be administered to assess neurocognitive impairment.

We found one notable difference between our patient population and those in other studies. The average IQ of our patients was 115, higher (107 and 108) than in other studies. ${ }^{10}{ }^{20}$ It is possible that the slightly higher incidence of neurocognitive impairment in our patients could be related to a higher premorbid IQ. One study found a higher composite neurocognitive score at baseline to be a significant predictor of change in the composite cognitive index.?

We thank Gwen Phillips (Department of Neuropsychology, University Hospital of Wales) for advice on the neuropsychometric tests

Contributors: $\mathrm{JH}$ and VZ had the original idea for the study and secured the funding. DW, VZ, and SK wrote the original protocol. JH coordinated the study. DW generated the allocation sequence and assigned participants to their allocation groups. VZ performed the operations. JD anaesthetised most of the patients and coordinated the collection of intraoperative data and blood samples. CC performed the neuropsychometric tests and collated the data. DW and SK coordinated the collection of follow up data. DW, SK, and JD recruited the patients. NP and VZ performed the statistical analyses and contributed to the interpretation of results. VZ wrote the original manuscript. All authors contributed to revisions of the manuscript. JH will act as guarantor for the paper.

Funding: The Welsh Office for Research and Development provided $£ 22000(\$ 34206$; €34,854) towards the study. It had no role in the conduct of the study, interpretation of the results, or the decision to send the study for publication.

Competing interests: None declared.

1 Keogh BE, Kinsman R on behalf of the Society of Cardiothoracic Surgeons of Great Britain and Ireland. National adult cardiac surgical database report 1999-2000; 133

2 Roach GW, Kanchuger M, Mangano CM, Newman M, Nussmeier N, Wolman R, et al. Adverse cerebral outcomes after coronary bypass surgery. N Engl J Med 1996;335:1857-63.

3 Vingerhoets G, Van Nooten G, Vermassen F, De Soete G, Jannes C. Short-term and long-term neuropsychological consequences of cardiac 
surgery with extra-corporeal circulation. Eur J Cardiothorac Surg 1997;11:424-31

4 Shaw PJ, Bates D, Cartlidge NEF, French JM, Heaviside D, Julian DG, et al. An analysis of factors predicting neurological injury in patients undergoing coronary bypass operations. OJ Med 1989;72:633-46.

5 McKhann GM, Goldsborough MA, Borowicz Jr LM, Selnes OA, Mellits D, Enger C, et al. Cognitive outcome after coronary artery bypass: a one-year prospective study. Ann Thorac Surg 1997;63:510-5.

6 Van Dijk D, Jansen EWL, Hijman R, Nierich AP, Diephuis JC, Moons KG, et al. Cognitive outcome after off-pump and on-pump coronary artery bypass graft surgery: a randomised trial. JAMA 2002;287:1405-12.

7 Newman MF, Kirchner JL, Phillips-Bute B, Gaver V, Grocott H, Jones RH, et al. Longitudinal assessment of neurocognitive function after coronary artery bypass surgery. $N$ Engl J Med 2001;344(6):395-402

8 Sontaniemi KA, Mononen MA, Hokkanen TE. Long-term cerebral outcome after open-heart surgery: a five year neuropsychological follow-up study. Stroke 1986;17:410-6.

9 Diegeler A, Hirsch R, Schneider F, Schilling LO, Falk V, Rauch T, et al. Neuromonitoring and neurocognitive outcome in off-pump versus conventional coronary bypass operation. Ann Thorac Surg 2000;69:1162-6.

10 Taggart DP, Browne SM, Halligan PW, Wade DT. Is cardiopulmonary bypass still the cause of cognitive dysfunction after cardiac operations? J Thorac Cardiovasc Surg 1999;118:414-21.

11 Lloyd CT, Ascione R, Underwood MJ, Gardner F, Black A, Angelini GD Serum S-100 protein release and neuropsychologic outcome during cor onary revascularization on the beating heart: a prospective randomized study.J Thorac Cardiovasc Surg 2000;119:148-54

12 Angelini GD, Taylor FC, Reeves BC, Ascione R. Early and midterm outcome after off-pump and on-pump surgery in beating heart against cardioplegic arrest studies (BHACAS 1 and 2): a pooled analysis of two dioplegic arrest studies (BHACAS 1 and 2): a pooled
randomised controlled trials. Lancet 2002;359:1194-9.

13 Zamvar V, Khan NU, Madhavan A, Kulatilake N, Butchart EG. Clinical outcomes in coronary artery bypass graft surgery: comparison of off-pump and on-pump techniques. Heart Surgery Forum 2002;5(2):109 13.
14 Murkin JM, Newman SP, Stump DA, Blumenthal JA. Statement of consensus on assessment of neurobehavioral outcomes after cardiac surgery. Ann Thorac Surg 1995;59:1289-95.

15 Nelson HE. National adult reading test (NART). Test manual. Windsor: NFER-Nelson, 1978.

16 Mahanna EP, Blumenthal JA, White WD, Croughwell ND, Clancy CP, Smith LR, et al. Defining neuropsychological dysfunction after coronary artery bypass grafting. Ann Thorac Surg 1996;61:1342-7.

17 Taylor KM. Cardiac surgery and the brain. In: Smith P, Taylor KM, ed. Cardiac surgery and the brain. London: Edward Arnold, 1993:1-14.

18 Blauth CI, Arnold JV, Schulenberg WE, McCartney AC, Taylor KM. Cerebral microembolism during cardiopulmonary bypass. Retinal microvascular studies in vivo with fluorescein angiography. J Thorac Cardiovasc Surg 1988;95:668-76.

19 Pugsley W, Klinger L, Paschalis C, Treasure T, Harrison M, Newman S. The inpact of microemboli during cardiopulmonary bypass on neuropsychological functioning. Stroke 1994;25:1393-9.

20 Borger MA, Peniston CM, Weisel RD, Vasiliou M, Green REA, Feindel CM. Neuropsychologic impairment after coronary bypass surgery: effects of gaseous microemboli during perfusionist interventions. J Thorac Cardiovasc Surg 2001;121:743-9.

21 Harris DNF, Bailey SM, Smith PLC, Taylor KM, Oatridge A, Bydder GM Brain swelling in first hour after coronary artery bypass surgery. Lancet 1993;342:586-7.

22 Gillinov AM, Davis EA, Curtis WE, Schleien CL, Koehler RC, Gardner TJ, et al. Cardiopulmonary bypass and blood brain barrier: an experimental study. J Thorac Cardiovasc Surg 1991;104:1110-5.

23 Westaby S, Saatvedt K, White S, Katsumata T, van Oeveren W, Bhatnagar $\mathrm{N}$, et al. Is there a relationship between $\mathrm{S}-100 \beta$ protein and neuropsychologic dysfunction after cardiopulmonary bypass? J Thorac Cardiovasc Surg 2000;119:132-7.

(Accepted 5 September 2002) 